\title{
Editorial
}

\section{Caesarean-Section and Neonatal Gut Microbiome: Short and Long Term Effects and New Targets for Early Prevention}

\author{
Antonietta Giannattasio Alfredo Guarino \\ Department of Translational Medical Science, Section of Pediatrics, University of Naples Federico II, Naples, Italy
}

The imprinting of intestinal microbiota is determined by several heterogeneous pre- and perinatal factors, including but not limited to the composition of the maternal microbiome [1], maternal nutrition and lactation [2], mode of birth [3], use of antibiotics [4] and length of gestation [5]. In turn microbiological microbiota will imprint the development of immunological asset of the host and have medium and long term consequences on health. Alterations in early gut microbiota are closely related to a risk for developing short-term diseases and chronic illnesses later in life.

Recent studies have emphasized the importance of the pregnancy period to the development of the neonatal microbiome. First, host-microbial interactions can impact host metabolism in pregnancy. Maternal gut microbiota changes dramatically from the first to the third trimester of pregnancy, with an overall increase in Proteobacteria and Actinobacteria, and reduced richness [6]. When transferred to germ-free mice, third trimester microbiota induced greater adiposity and insulin insensitivity compared to first trimester [6]. Second, it was generally considered that the intrauterine environment and newborn were sterile until delivery. Emerging evidence indicate that transmission of microbiota from mother to offspring may occur before delivery. Bacteria have been found in meconium [7], amniotic fluid [8], and placenta [9]. At birth, once the neonate is exposed to several new mi-

\section{KARGER}

(c) 2018 S. Karger AG, Basel

E-Mail karger@karger.com

www.karger.com/anm crobes, the gut undergoes a rapid microbial colonization. The gut microbiota composition of early infants has low diversity and it is dynamic [10]. The earliest colonizers are predominantly facultative anaerobes (Escherichia coli, Enterococcus), which, as oxygen is consumed, give way to strict anaerobes, including Bifidobacterium, Lactobacillus, Bacteroides, Clostridium, and less often, Ruminococcus [11]. Third, the mode of birth determines the microbial population that infants are exposed to during delivery [12]. Vaginal delivery exposes infants to microbes that are colonizing the mother's birth canal. In contrast, environmental factors (e.g., delivery and surgical equipment, air, other infants and healthcare workers) appear to have a greater effect on the microbiome of infants born by caesarian-section [13]. Caesarean-born infants are at risk for being colonized by aberrant microbiota and may even be a reservoir of toxigenic Clostridium perfringens [14].

The balance between the microbiota, immune response, and tolerance mechanisms is essential for newborn gut health. Disruption of the normal neonatal intestinal bacterial flora is an established risk for neonatal necrotizing enterocolitis (NEC) in preterm infants. Patients with NEC present low gut microbial diversity, increased Proteobacteria, and decreased Firmicutes numbers [15]. Breastfeeding is associated with a reduced risk of NEC. Human milk oligosaccharides seem to have a double protective effect: to generate a protective microbiota and to 
reduce the incidence of NEC on its own [16]. Several trials have investigated the use of probiotics to prevent NEC with a variety of probiotic preparations. A recent metaanalysis has shown that preterm infants benefit from probiotics to prevent severe NEC and death [17]. However, a species-specific treatment recommendation could not be made because of the heterogeneity of organisms and dosing regimens studied. On the other hand, some negative studies have been published. A rigorous randomized controlled trial in UK showed no effect of a putative effective Bifidobacterium breve strain on mortality or NEC in a large group of preterm infants [18]. Another very recent study reported no effect on the risk of NEC of routine LGG supplementation [19]. However, this was a retrospective observational cohort study. In order to determine the most effective strain which is more relevant to the clinician, a network meta-analysis (NMA) approach has been recently applied [20]. This NMA showed efficacy in reducing mortality and morbidity in a minority of the studied strains or combinations. This may be due to an inadequate number, or size, of randomized controlled trial, or due to a true lack of effect for certain species. It was not possible to determine optimal probiotic dosages, time of initiation, and duration of treatment course [20]. However, this strain-specific NMA approach will give a much more meaningful answer than meta-analyses in which all probiotic strains are analysed as one group.

Finally, most studies agree on recognizing dysbiosis as a risk factor associated with many pediatric diseases [21]. Lower microbial diversity in early infancy seems to lead the way for the development of allergic manifestations as asthma [22, 23]. Modifications of intestinal microbiota seems to be linked to a high risk to develop respiratory infection. In this context, it has been reported that the early administration of galacto-oligosaccharide/polydextrose formula has a protective effect against infec- tions and atopy in at risk infants [24]. Early-life changes in gut microbiota composition can alter susceptibility to developing obesity later in life [25]. In addition, changes in gut microbiota composition may influence the development of autoimmune disorders in children, including type 1 diabetes and inflammatory bowel disease $[26,27]$. Early life is a crucial period for health and represent a stage in which interventions for disease prevention should be applied. Changes in newborn microbiota composition induced by physiological events (maternal diet, vaginal delivery, breast milk) or medical interventions (prebiotics or probiotics administration) may beneficially affect future child's health. Preventive and therapeutic strategies should be looked for to prevent short and longterm diseases due to disruption of the early gut microbiome. In this context, the purpose of this special issue is to provide updated information on the impact of caesariansection on gut microbiota composition in healthy infants, on its effect on immune system and on the consequences for future health, and to contribute to a better knowledge of possible interventions to counteract neonatal disbiosis and exploit intestinal microbiota for clinical purposes. A solid, honest and effective scientific approach will produce effective or less effective but reliable results, keeping in mind the important consequences of translating science to practice on survival rates of preterms and on future health of all neonates. Based on science the subsequent challenge will be the application of indications provided by authoritative guidelines [28].

\section{Disclosure Statement}

Prof. Guarino has received honoraria for his participation on the board of Biocodex France. He has also received a research grant from Dicofarm. Dr. Giannattasio has nothing to disclose.

\section{References}

1 Gohir W, Ratcliffe EM, Sloboda DM: Of the bugs that shape us: Maternal obesity, the gut microbiome, and long-term disease risk. Pediatr Res 2015;77:196-204.

2 Chu DM, Meyer KM, Prince AL, Aagaard KM: Impact of maternal nutrition in pregnancy and lactation on offspring gut microbial composition and function. Gut Microbes 2016;7:459-470.

3 Neu J, Rushing J: Cesarean versus vaginal delivery: long-term infant outcomes and the hygiene hypothesis. Clin Perinatol 2011;138: 321-331.
4 Zou ZH, Liu D, Li HD, Zhu DP, He Y, Hou T, Yu JL: Prenatal and postnatal antibiotic exposure influences the gut microbiota of preterm infants in neonatal intensive care units. Ann Clin Microbiol Antimicrob 2018;17:9.

5 Itani T, Ayoub Moubareck C, Melki I, Rousseau C, Mangin I, Butel MJ, Karam Sarkis D: Establishment and development of the intestinal microbiota of preterm infants in a Lebanese tertiary hospital. Anaerobe 2017;43:4-14.

6 Koren O, Goodrich JK, Cullender TC, Spor A, Laitinen K, Backhed HK, Gonzalez A, Werner JJ, Angenent LT, Knight R, et al: Host remodel- ing of the gut microbiomeand metabolic changes during pregnancy. Cell 2012;150:470-480.

7 Jiménez E, Marín ML, Martín R, Odriozola JM, Olivares M, Xaus J, Fernández L, Rodríguez JM: Is meconium from healthy newborns actually sterile? Res Microbiol 2008; 159:187-193.

8 DiGiulio DB, Romero R, Amogan HP, Kusanovic JP, Bik EM, Gotsch F, Kim CJ, Erez O, Edwin S, Relman DA: Microbial prevalence, diversity and abundance in amniotic fluid during preterm labor: a molecular and culturebased investigation. PLoS One 2008;3:e3056. 
9 Collado MC, Rautava S, Aakko J, Isolauri E, Salminen S: Human gut colonisation may be initiated in utero by distinct microbial communities in the placenta and amniotic fluid. Sci Rep Sep 2016;6:23129.

10 Castanys-Muñoz E, Martin MJ, Vazquez E: Building a beneficial microbiome from birth. Adv Nutr 2016;7:323-330.

11 Penders J, Thijs C, Vink C, Stelma FF, Snijders B, Kummeling I, van den Brandt PA, Stobberingh EE: Factors influencing the composition of the intestinal microbiota in early infancy. Pediatrics 2006;118:511-521.

12 Chong CYL, Bloomfield FH, O'Sullivan JM: Factors affecting gastrointestinal microbiome development in neonates. Nutrients 2018; 10:E274.

13 Martin R, Makino H, Cetinyurek Yavuz AC, Ben-Amor K, Roelofs M, Ishikawa E, Kubota H, Swinkels S, Sakai T, Oishi K, et al: Early-life events, including mode of delivery and type of feeding, siblings and gender, shape the developing gut microbiota. PLoS One 2016; 11:e0158498.

14 Nagpal R, Tsuji H, Takahashi T, Nomoto K, Kawashima K, Nagata S, Yamashiro Y: Gut dysbiosis following C-section instigates higher colonisation of toxigenic Clostridium perfringens in infants. Benef Microbes 2017; 8:353-365.

15 Torrazza RM, Neu J: The altered gut microbiome and necrotizing enterocolitis. Clin Perinatol 2013;40:93-108.
16 Jantscher-Krenn E, Zherebtsov M, Nissan C, Goth K, Guner YS, Naidu N, Choudhury B, Grishin AV, Ford HR, Bode L: The human milk oligosaccharide disialyllacto-n-tetraose prevents necrotising enterocolitis in neonatal rats. Gut 2012;61:1417-1425.

17 Sawh SC, Deshpande S, Jansen S, Reynaert CJ, Jones PM: Prevention of necrotizing enterocolitis with probiotics: a systematic review and meta-analysis. Peer J 2016;4:e2429.

18 Costeloe K, Hardy P, Juszczak E, Wilks M, Millar MR: Bifidobacterium breve BBG-001 in very preterm infants: a randomised controlled phase 3 trial. Lancet 2016;387:649-660.

19 Kane AF, Bhatia AD, Denning PW, Shane AL, Patel RM: Routine supplementation of lactobacillus rhamnosus GG and risk of necrotizing enterocolitis in very low birth weight infants J Pediatr 2018;195:73-79.

20 van den Akker CHP, van Goudoever JB, Szajewska H, Embleton ND, Hojsak I, Reid D, Shamir R; ESPGHAN Working Group for Probiotics, Prebiotics \& Committee on Nutrition: Probiotics for preterm infants: a strainspecific systematic review and network metaanalysis. J Pediatr Gastroenterol Nutr 2018; 67:103-122.

21 Ranucci G, Buccigrossi V, de Freitas MB, Guarino A, Giannattasio A: Early-life intestine microbiota and lung health in children. J Immunol Res 2017;2017:8450496.

22 Wopereis H, Oozeer R, Knipping K, Belzer C, Knol J: The first thousand days-intestinal mi- crobiology of early life: establishing a symbiosis. Pediatr Allergy Immunol 2014;25:428438.

23 Chu S, Yu H, Chen Y, Chen Q, Wang B, Zhang J: Periconceptional and gestational exposure to antibiotics and childhood asthma. PLoS One 2015;10:e140443.

24 Ranucci G, Buccigrossi V, Borgia E, Piacentini D, Visentin F, Cantarutti L, Baiardi P, Felisi M, Spagnuolo MI, Zanconato S, Baraldi E, Giaquinto C, Guarino A: Galacto-oligosaccharide/polidextrose enriched formula protects against respiratory infections in infants at high risk of atopy: a randomized clinical trial. Nutrients 2018;10:E286.

25 Azad MB, Bridgman SL, Becker AB, Kozyrskyj AL: Infant antibiotic exposure and the development of childhood overweight and central adiposity. Int J Obes 2014;38:12901298.

26 McLean MH, Dieguez D Jr, Miller LM, Young HA: Does the microbiota play a role in the pathogenesis of autoimmune diseases? Gut 2015;64:332-341.

27 Hviid A, Svanstrom H, Frisch M: Antibiotic use and inflammatory bowel diseases in childhood. Gut 2011;60:49-54.

28 Cameron D, Hock QS, Kadim M, Mohan N, Ryoo E, Sandhu B, Yamashiro Y, Jie C, Hoekstra H, Guarino A: Probiotics for gastrointestinal disorders: proposed recommendations for children of the Asia-Pacific region. World J Gastroenterol 2017;23:7952-7964. 